\title{
Cefaléia em Salvas Diagnóstico e Tratamento
}

\author{
Suzanmeire N.Minatti-Hannuch ${ }^{1}$, Eliova Zukerman ${ }^{2}$ \\ Jony de Andrade Sobrinho
}

\section{RESUMO}

Săo apresentados os principais elementos diagnósticos da Cefaléia em Salvas bem como das celaléias incluidas item 3 da Classificaçăo da international Headache Society. Após uma súmula dos principais aspectos clínicos e fisiopatológicos, são abordados o tratamento da crise $\theta$ a profilaxia desta forma de cefaléia primária.

\section{UNITERMOS}

Cefaléia em salvas - Diagnóstico - Tratamento
Doutora em Neurologia - Disciplina de Neurologia da Escola Paulista de Medicina

2 Professor Adjunto a Chefe do Setor de Investigaçăo e Tratamento das Cefaléias (SITC) da Disciplina de Neurologia da Escola Paulista de Medicina

3 Pós-Graduando de Neurologia da Escola Paulista de Medicina
A síndrome da Cefaléia em Salvas recebeu, desde suas primeiras descrições numerosos nomes, entre os quais podem ser citados: Enxaqueca vermelha, Hemicrania angioparalítica, Neuralgia migranosa paralítica, Neuralgia migranosa periódica, Fasciocefalalgia Histamínica e Cefalalgia Histamínica ou de Horton.

"Cluster Headache", traduzido como Cefaléia em Salvas (CS) parece mais apropriada por caracterizar o padrão de evolução temporal das crises, indicando importante parâmetro para o diagnóstico e tratamento.

A prevalência, pouco estudada em nosso meio, está em torno de 69 casos por 100. 000 habitantes $(2)$. O diagnóstico deve ser feito prontamente em função do intenso sofrimento a que o paciente está submetido em cada crise. Existe um nítido predomínio deste síndrome no sexo masculino, em proporções de 4 a 5 homens para uma mulher acometida. As razões deste predomínio ainda não estão esclarecidas.

Podem ser acometidos pacientes de qualquer idade, sendo o mais jovem relato o de um paciente de 3 anos. É sabido entretanto que exitem picos de maior frequencia a partir da quarta década, podendo extender-se até a quinta ou sexta décadas.

Conceitualmente, trata-se de cefaléia unilateral que raramente muda de lado durante um mesmo surto ( $2 \%$ ) e de lado de um surto para outro( $10 \%)$ As regiōes mais afetadas são a frontal e ocular mas são descritas variedades importantes comprometendo a metade inferior da face.

A International Headache Society(1) definiu critérios diagnósticos para a CS que estão expressos no Quadro 1:

\begin{tabular}{|l|}
\hline \multicolumn{1}{|c|}{ A. Pelo menos 5 crises preenchendo os critérios de B a D. } \\
\hline B. Dor intensa, unilateral, orbital, supraorbital e ou temporal que, não tratada, dura de \\
$\qquad 15$ a 180 minutos. \\
\hline C. Cefaléia asociada a um dos seguintes sinais: \\
1. injeção conjuntival \\
2. lacrimejamento \\
3. conjestâo nasal \\
4. rinorréia \\
5. sudorese frontal e facial \\
6. miose \\
7. ptose \\
8. edema da pálpebra \\
\hline D. Freqüência das crises: de 1 a 8 por dia \\
\hline E. História, exame clínico, neurológico bem como investigações apropriadas que \\
descartem cefaléias sintomátcas. \\
\hline Quadro 1 : Critérios diagnósticos para a CS. \\
\hline
\end{tabular}


Entre os vários subtipos clínicos de CS, embora as manifestaçōes clínicas sejam semelhantes, é a diposição destas crises no tempo que permite a diferenciação diagnóstica. No Quadro 2 estas diferenças estão relacionadas.

\begin{tabular}{|c|c|}
\hline Nome & particularidade \\
\hline CS & $\begin{array}{c}\text { periodicidade não } \\
\text { determinada(o tempo ainda não } \\
\text { permite classificar) }\end{array}$ \\
\hline CS episódica & $\begin{array}{c}\text { ocorre em periodo que duram de } \\
\text { 7 dias a um ano, separadas por } \\
\text { intervalos livres de dor que } \\
\text { duram 14 dias ou mais. }\end{array}$ \\
\hline CS crônica & $\begin{array}{c}\text { crises ocorrem por mais de um } \\
\text { ano, com ou sem remissão que } \\
\text { dura menos de 14 dias }\end{array}$ \\
\hline CS crônica & $\begin{array}{c}\text { anteriormente denominada } \\
\text { forma "primária", por já ter } \\
\text { início sem remissão, crốnico. }\end{array}$ \\
\hline CS crônica & $\begin{array}{c}\text { anteriormente chamada } \\
\text { crônica secundária por ter } \\
\text { evoluido de uma forma primária }\end{array}$ \\
\hline Quadro 2: Distribuição temporal das formas clínicas de CS. \\
\hline
\end{tabular}

O interesse no conhecimento dos detalhes de classificação baseia-se principalmente no fato de que alguns medicamentos são mais eficazes em uma forma clínica que em outra.

\section{Aspectos fisiopatológicos}

Os principais aspectos a serem explicados são a origem da dor e dos fenomenos acompanhantes bem como a ocorrência do Síndrome de Horner.

Acredita-se que o trato espinal e o núcleo trigeminal, chegando até os níveis da segunda vértebra cervical, tornem-se unilateralmente hiperativos durante a crise e que a principal fonte de dor seja a artéria carótida interna e seus ramos proximais. Existem várias evidências de que ocorre dilatação destes vasos, incluindo também a artéria oftálmica, sem alterações consistentes no fluxo sanguíneo cerebral. Os capilares dilatamse na conjuntiva, mucosa nasal e na circulação cutânea principalmente na área periorbital.

Quanto à explicação do Síndrome de Horner parcial encontrado na CS, aceita-se que seja decorrente do edema na parede da artéria carotida interna comprometendo os neurônios simpáticos pós ganglionares no plexo perivascular.

Outros fenômenos como o predomínio no sexo masculino, o despertar em crise durante o sono REM , a periodicidade das crises e outros, ainda não possuem explicações satisfatórias, sendo que o envolvimento hipotalamico é muito provável.

\section{Diagnóstico diferencial}

Devem ser consideradas várias entidas clínicas, iniciandose pelos quadros chamados de "Cluster-like", bastante raros mas já descritos em associação a sinusopatias, malformaçōes vasculares, dissecção de artéria carótida, tumores hipofisários, meningeoma da asa do esfenoide.

Outros diagnósticos diferenciais devem ser feitos com Neuralgia do Trigemio, Síndrome Cluster-tic, Hemicrania paroxística crônica, Neuralgias faciais atípicas, Glaucoma, Síndrome de Tolosa-Hunt, Carotidínea, Sindrome de Costen, Cefalalgia disautonômica pos-traumática $(3,4)$.

Deve-se supeitar de síndrome "Cluster-like" sempre que a dor excede a duração habitual, os fenômenos acompanhantes não são os mais frequentemente observados, a periodicidade não está mantida. Nestes casos a investigação por método de imagem é obrigatória.

\section{Tratamento}

O tratamento deve ser instituído de imediato. As principais medidas para o tratamento da crise estão relacionadas no Quadro 3.

\begin{tabular}{|c|c|}
\hline fármaco/dose & observações \\
\hline $\begin{array}{c}\text { Inalação de Oxigenio } \\
8 \text { a } 10 \text { litros por minuto }\end{array}$ & $\begin{array}{c}\text { Fazer a inalação com máscara } \\
\text { Eficaz em 60 a 80\% dos casos. } \\
\text { Inalar por 5 a 15 minutos }\end{array}$ \\
\hline $\begin{array}{c}\text { Derivados do ergot } \\
\text { a } 2 \text { mg } \\
\text { via oral ou nasal }\end{array}$ & $\begin{array}{c}\text { Usado no inicio da crise ou } \\
\text { quando a crise tem horário de } \\
\text { aparecimento regular. Neste } \\
\text { caso, usar 30 minutos antes. }\end{array}$ \\
\hline $\begin{array}{c}\text { Suté 6mg via subcutânea } \\
\text { 100 mg por via oral }\end{array}$ & $\begin{array}{c}\text { Não usar em associação a } \\
\text { derivados do ergot. }\end{array}$ \\
\hline $\begin{array}{c}\text { Analgésicos comuns e } \\
\text { analgésicos narcóticos }\end{array}$ & Eficácia discutivel \\
\hline \multicolumn{2}{|c|}{ Quadro 3: Tratamento da crise de CS. } \\
\hline
\end{tabular}

Ainda na crise os autores tem preconizado o uso de Lidocaína a $2 \%$ por via intranasal, na dose de $1 \mathrm{cc}$ cada 15 ou 30 minutos, na narina ipsilateral à dor, no máximo tres vezes por crise $(5,6)$.

A indicação do tratamento profilático se faz:quando não há sucesso no abortamento da crise pelas medidas propostas nesta fase. Outra indicação é a persistência de crises que despertam o paciente, crises que não cessam totalmente com o tratamento. De maneira geral institui-se a profilaxia quase de rotina embora os mecanismos de ação propostos para cada um dos profiláticos ainda seja muito controverso.

No Quadro 4 encontramos as principais substancias utilizadas na profilaxia da CS.

\begin{tabular}{|c|c|}
\hline fármaco/dose & Comentários \\
\hline $\begin{array}{c}\text { Metisergida } \\
2 \text { a } 4 \text { mg/dia }\end{array}$ & $\begin{array}{c}\text { Não usar mais que 5 meses sem } \\
\text { interrupção Aumentar doses } \\
\text { progressivamente. }\end{array}$ \\
\hline $\begin{array}{c}\text { Verapamil } \\
160 \text { a 480 mg }\end{array}$ & $\begin{array}{c}\text { Aumento e redução gradativas } \\
\text { da dose }\end{array}$ \\
\hline $\begin{array}{c}\text { Valproato de sodio } \\
\text { 600 a 1200mg/dia }\end{array}$ & $\begin{array}{c}\text { Melhores resultados na forma } \\
\text { episódica. }\end{array}$ \\
\hline $\begin{array}{c}\text { Carbonato de lítio } \\
\text { 300 a 900mg/dia. }\end{array}$ & $\begin{array}{c}\text { Monitorização dos níveis séricos } \\
\text { de lítio }\end{array}$ \\
\hline $\begin{array}{c}\text { Pizotifeno } \\
\text { 2 a 3 mg/dia }\end{array}$ & Até 57\% de respostas favoráveis. \\
\hline Prednisona & 75 a 1mg/kg/dia \\
\hline 0 & Quadro 4: Principais profiláticos para tratamento da CS. \\
\hline
\end{tabular}


Muitas outras substâncias podem ser utilizadas como profiláticos da $\operatorname{CS}(4,5,6)$. Entre eles, citam-se os derivados do ergot, principalmente o tartarato de ergotamina em doses de até $3 \mathrm{mg} / \mathrm{dia}$. Neste caso deve ser feito uso por poucos dias em função dos graves efeitos colaterais do uso excessivo dos derivados do ergot.

Alguns autores preconizam o uso de corticosteróides como a principal medida profilática. São utilizadas a Metilprednisolona, Triancinolona, Dexametasona bem como a Betametasona. Atenção especial deve ser dada aos efeitos colaterais decorrentes do uso prolongado.

Citam-se ainda a Clorpromazina, o Lisuride, Cimetidina, Bloqueadores dos receptores $\mathrm{H} 1$ e Nimodipina.

As associações mais eficazes parecem ser aquelas feitas entre os profiláticos citados com os corticosteroides, à exceção do carbonato de lítio.

O tratamento cirúrgico está indicado apenas nos casos onde não houve sucesso nas tentativas de tratamento clínico. Os resultados da abordagem cirúrgica são pouco numerosos e incertos. As alternativas disponíveis referem-se à Neurectomia occipital ou à descompressão, secç̧ão dos nervos Intermédio e Grande Petroso Superficial. Os resultados também são parciais e transitórios na maioria dos pacientes. Métodos mais tradicionais de abordagem cirúrgica tais como a Termocoagu- lação do Ganglio de Gasser ou a secção parcial da raíz sensitiva do Nervo Trigemio resultaram também em alívio parcial e tramsitórios dos sintomas e sinais.

\section{SUMMARY}

The main clinical and pathophysiologic aspects of Cluster Headache (item 3 of the Classification of the International Headache Society) were considered. The treatment of the attack and the prophylaxis of this primary headache were discussed.

\section{KEY WORDS}

Cluster Headache - Diagnosis - Treatment

\section{Bibliografia}

1. Classificaçāo da international Hedache socieety

2. LANCE, J. W. - Mechanism and management of headache. Butterworth-heinemann, Oxford, $5^{\circ} \mathrm{ed}$, capitulo 12, pg 163-183, 1993.

3. RASKIN, N. H. - Headache. New York: Churchill Livingstone, 1988.

4. VINKEN, P. J. \& BRUYIN, G. W. - Headache. Amsterdan: Eisevier, v. $48,1985$.

5. JOHNSON, T. R. \& GRIFFIN, J. W. - Current Therapy in Neurological Disease. St. Louis:Mosby year book, 1993.

6. EADIE, M. J. - Drug Therapy in Neurology. Edinburgh: Churchill Livingstone, 1992.

\section{Tegrefolion}

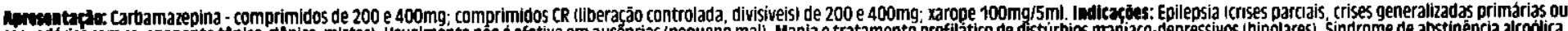

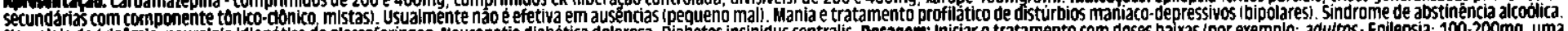

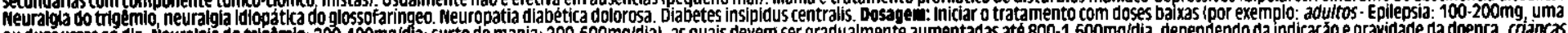

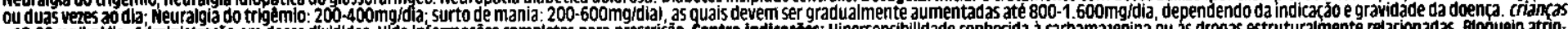

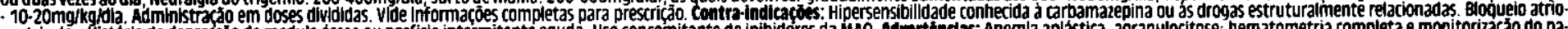

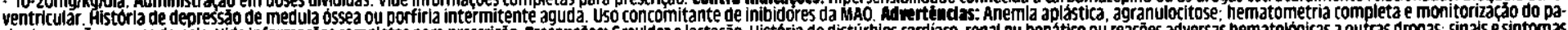

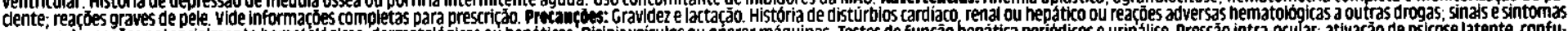

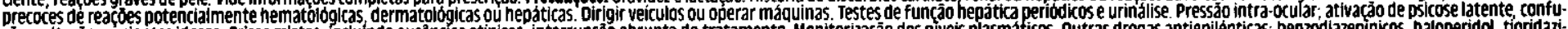

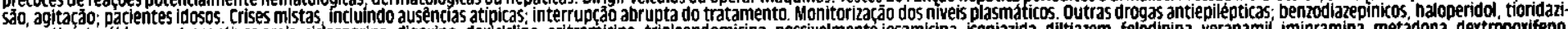

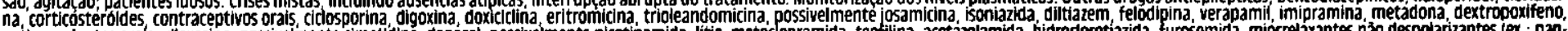

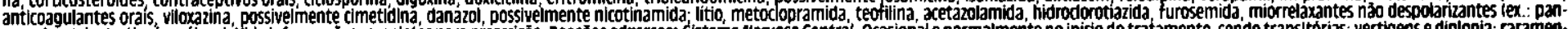

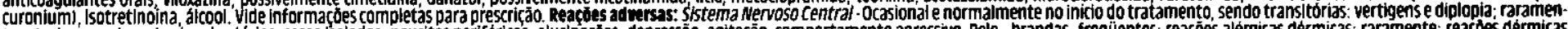

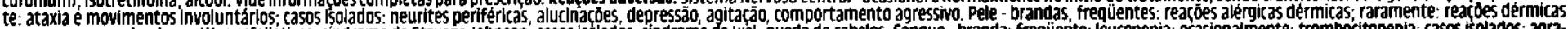

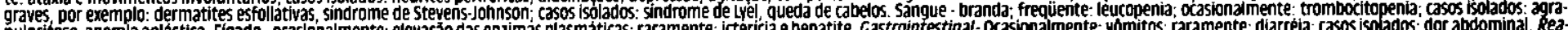

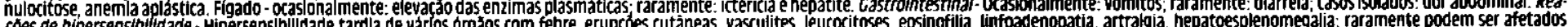

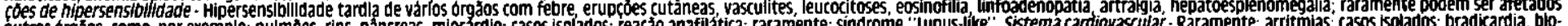

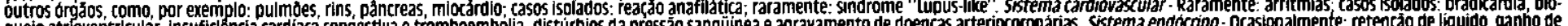

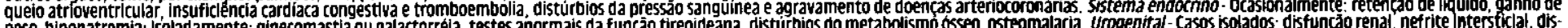

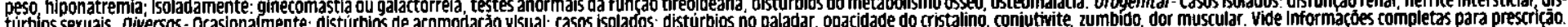

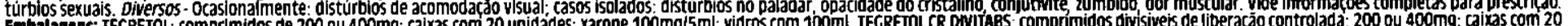
Embalago 